\title{
Vassouras - \\ Origens do Povoado até o Centenário de Elevação a Cidade
}

\author{
Angelo Ferreira Monteiro \\ Membro Titular da Academia de Letras de Vassouras, Membro \\ Colaborador do Instituto Histórico e Geográfico de Vassouras e \\ Pesquisador Independente \\ angelofmonteirodgmail.com
}

\begin{abstract}
Resumo: Este trabalho pretende focalizar as origens do povoado de Vassouras, desde a escolha do local da criação da vila com as obras realizadas pelos seus primeiros gestores municipais no século XIX. Dentre elas, destacamos a criação da Estrada de Ferro Pedro II, objetivando transformar Vassouras em uma cidade modelo, da então Província do Rio de Janeiro. Nos primeiros anos do período republicano, surgiu um projeto na Assembleia Legislativa, com a proposta de transferência da capital do Estado do Rio de Janeiro, onde o então deputado Sebastião de Lacerda indicou a cidade de Vassouras em substituição a Teresópolis, justificando que a primeira já possuía os prédios públicos necessários para a transferência. Infelizmente o projeto não foi à frente. Mas, foi durante os preparativos para as comemorações do centenário de elevação à cidade no ano de 1933, durante a administração do Prefeito Maurício Paiva de Lacerda, filho de Sebastião de Lacerda, que a cidade sofreu ajustes na sua urbanização, a fim de torná-la uma cidade turística, o que provocou o descontentamento dos moradores do municipio, que não compreenderam os projetos propostos.
\end{abstract}

Palavras-chave: Cidade de Vassouras. Origens. Urbanização.

\section{Vassouras - \\ Dépuis ses Origines Jusqu’à L'occasion Du Centenaire de Son Élévation à Ville}

Résumé: Cet article se propose de mettre l'accent sur les origines du village de Vassouras, dela choisie du site de la création du village, pour les travaux effectués par ses premiers gestionnaires municipaux au XIX e siècle. Parmi eux, nous mettons en évidence la création de la Railroad Pedro II, visant à transformer la ville de Vassouras en une ville modèle, à la Province de Rio de Janeiro. Dans les premières années de la période républicaine, il y avait un projet à l'Assemblée législative, avec la proposition de transférer la capitale de 


\begin{abstract}
l'État de Rio de Janeiro. Monsieur le Député Sebastião de Lacerda a indiqué la ville de Vassouras, au lieu de la ville de Teresopolis, expliquant que la première avait des bâtiments publics nécessaires pour le transfert. Malheureusement, le projet n'était pas en avance. Mais, c'est pendant les préparatifs de la célébration du centenaire de l'élévation à la ville en 1933, sous l'administration du maire Mauricio Paiva Lacerda, fils de Sebastião de Lacerda, que la ville a subi ses ajustements en l'urbanisation pour se rendre une ville touristique, ce qui a provoqué le mécontentement des résidents de la municipalité, qui ne comprenait pas les projets proposés.
\end{abstract}

Mots-clés: La ville de Vassouras. Origines. Urbanisation.

\title{
O Caminho Novo
}

O presente trabalho pretende focalizar o início da urbanização do Município de Vassouras. Para tanto, temos que retornar aos motivos que levaram à escolha do local para a criação do rocio, da então Vila de Vassouras, antes Termo da Vila de Paty de Alferes, esta por sua vez criada em 1820.

Em estudo recente, Francisco Veríssimo (2008, p. 378), defende que o fator primordial para o desenvolvimento de Vassouras foi a localização do sítio ao sopé da Serra do Mar no início do Vale do Rio Paraíba, ponto ideal para o descanso das tropas de mulas que faziam o trajeto entre a região de Minas e a cidade do Rio de Janeiro, pelo chamado Caminho Novo das Minas. Foi responsável pelo início deste empreendimento Garcia Rodrigues Paes, que o abriu por volta de 1698 e o concluiu em 1705, tendo como ponto de partida as suas próprias roças, na região conhecida como Ressaca, depois denominada Estrada Real (FERNANDES, 2004. p. 23-24). Anteriormente o percurso era feito pelo Caminho Velho - compreendido entre a vila de Parati e a Serra do Mar, onde se seguia a rota em direção às Minas Gerais (FERNANDES, 2004. p. 23-24).

Além do Caminho Novo, criaram-se também algumas variantes. Estas vias alternativas em determinado momento se uniam, pois a diferença estava na escolha de ir pelo mar e alcançar o rio, ou ir sempre por terra ${ }^{1}$.

Para se chegar à roça do Alferes (Paty do Alferes) pelo Caminho Novo eram necessárias seis jornadas ${ }^{2}$.

Vale citar que, antes da criação da Vila de Paty do Alferes, a freguesia teve a sua Igreja Matriz construída em três lugares diferentes, tudo devido a questões políticas entre os fazendeiros locais, que não queriam ver nascer em suas terras a sede administrativa da Vila ${ }^{3}$.

Em 1750, foi criada a Freguesia de Nossa Senhora da Conceição de Sacra Família do Caminho Novo do Tinguá, que em 1837, foi dividida com a Freguesia de Nossa Senhora da Conceição de Vassouras, passando esta última a ser responsável pelos registros paroquiais. 


\section{A Sesmaria de Vassouras e Rio Bonito}

Vassouras surgiu da Fazenda das Vassouras ${ }^{4}$ (em alguns documentos Bassura ${ }^{5}$ ), que compõe a Sesmaria de Vassouras e Rio Bonito (em algumas fontes primárias consta como Bassouras e Bonito $^{6}$ ), de propriedade dos açorianos Francisco Rodrigues Alves e Luiz Homem de Azevedo 7 . Em 23 de março de 1823, o Guarda-Mor, José Teixeira Gomes e sua mulher Ana Maria do Espírito Santo, fizeram a doação de 360 braças de testada para a Estrada que margeava o Rio das Mortes (atual distrito de Barão de Vassouras), para o patrimônio de Nossa Senhora da Conceição.

Através de um Termo de Ratificação José Joaquim Extrexe, sua mulher e outros herdeiros do Guarda-Mor e mais uma Permuta de Terrenos, com Francisco José Teixeira Leite posteriormente, Comendador e Barão de Vassouras - e sua mulher, realizada em 1830, por escritura pública ${ }^{8}$, pôde a Vila ser erigida no local que hoje conhecemos como Centro Histórico de Vassouras - tombado pelo IPHAN (Instituto de Patrimônio Histórico e Artístico Nacional) em $1958^{9}$.

Verificando que havia dúvida nos marcos divisórios da Sesmaria de Vassouras e Rio Bonito, o Guarda-Mor, João Teixeira Gomes e outros herdeiros de Luiz Homem de Azevedo, de Fellis Rodrigues Alves e de seu filho Francisco Rodrigues Alves, solicitaram, em 1818, ao Juiz das Sesmarias da Corte e Cidade de São Sebastião do Rio de Janeiro e Cavaleiro da Ordem de Cristo, Dr. Manoel Rodrigues Pacheco e Moraes, a abertura de uma ação judicial de medição, demarcação e aviventação dos marcos e rumos da referida sesmaria. Para tanto, solicitaram a citação dos confrontantes e confinantes das ditas terras

\footnotetext{
... o Brigadeiro Ambrozio de Souza Coutinho e sua mulher Dona Joanna por si [ilegível] Tutor de seus netos e filhos do finado Coronel Bento Luiz de Oliveira Braga, e ao Doutor José Clemente Pereira e sua mulher Dona Francisca Marianna de Oliveira Coutinho, viúva do dito finado Coronel Bento Luiz e os órfãos do dito e maiores de quatorze anos Dona Maria e Dona Francisca e o [ilegível] Antonio da Roza Pinheiro e sua mulher Anna Gertrudes [Medição e Demarcação - 1818. Partes: José Teixeira Gomes e Antonio Alves de Lacerda (autores); Luiz Homem de Azevedo e Fellis Rodrigues Alves (falecidos). Sesmaria de Bassouras e Rio Bonito - Vassouras. Documento Incompleto. (Código 101663451016)].
}

O Juiz se fazia presente com todo o aparato necessário: Escrivão, Oficiais do Juízo, o Piloto e seu ajudante ${ }^{10}$. Dois dias após o reconhecimento do marco inicial deu-se início à medição. No primeiro dia mediram-se 815 braças; no seguinte, 605 braças; no terceiro 650 braças e no quarto 725 braças, que totalizaram 2.795 braças.

No primeiro dia da demarcação, percebeu-se que não houve a presença de ninguém que se opusesse a esta ação. Os autores por sua vez, deixaram bem claro, que não queriam complicações com pessoa alguma e muito menos com a Real Fazenda de Santa Cruz, visto que, na época da medição extrajudicial, feita pelo antigo Piloto Fellis Alves, seguindo a direção do lado sul, a dita demarcação foi encravar no terreno da medição de Santa Cruz, hoje bairro da cidade do Rio de Janeiro.

Após o encerramento das atividades, foi feito o relatório sobre a demarcação e o termo de 
configuração da sesmaria e mais declarações ${ }^{11}$ que se faziam necessárias:

\begin{abstract}
configuram o polígono Heptágono por ter 07 lados com o Rio nos fundos, e que dentro da superfície compreendia 838.679 braças quadradas vindo a faltar para o preenchimento da Régia Comissão 361.321 braças quadradas que por não haver terreno devoluto senão pode preencher, cujo (...) feito por ele piloto aos rumos e bases do Rio e triângulos e dentro da mesma superfície ficavam mais de 20 fogos dos moradores herdeiros e seus agregados foram outros metidos no mato que ele Piloto com os rumos os não avistou, e além destes fogos muito paióis, senzalas, roças, cafezais e capoeiras e que a linha de testada (...) corria do rumo de Sudoeste e seu oposto Nordeste angulo 43 magnético tendo-se mesma linha 3.550 braças em sua extensão a saber 2.795 braças seguindo pela picada e rumo e marco da medição antiga feita extrajudicial do Piloto Fellis Alves 755 braças que se foram buscar para o preenchimento e também para unir esta quadra a Fazenda medida de Santa Cruz que por averiguações (...) [não] estar a mesma Real Fazenda de Santa Cruz medida entrando pelo terreno dos autores. [Interdito Proibitório - 1934. Prefeitura Municipal de Vassouras (suplicada). (Código 103666132021)].
\end{abstract}

Na lateral deste relatório, consta a observação que as 3.550 braças medidas na testada, eram necessárias para se não entrar na Fazenda Santa Cruz, como se entrou na medição extrajudicial realizada em 1786.

Entretanto, um dos confrontantes, o Dr. Clemente José Pereira ${ }^{12}$, verificou que ,durante a medição, entraram em sua propriedade. Justificou que a Sesmaria já havia sido medida em 1786 e que não podia conceber uma nova medição, pois com esta atitude, invadiam suas possessões antigas, em mais de meia légua, na qual possuía benfeitorias e posse efetiva, como comprovava com os documentos juntos e que os autores da ação, foram favorecidos nas quatro linhas da Sesmaria em mais de 30.000 braças. Via a necessidade de uma nova medição e ainda alfineta, dizendo

\footnotetext{
Porque e quando aquele deficit fosse verdadeiro, e não procedesse da Corda de palmos acrescentados, ou de corda estendida com mão generosa a favor dos Embargados ou por que aponto certo do seu começo não foi bem averiguado, em nenhum caso tem os Embargados direito de se indenizarem pelas possessões dos Embargantes.
}

Porque os títulos dos Embargados não tem a força necessária para dar aos mesmos Embargados mais terreno, que aquele que ocupavam com suas posses, e benfeitorias efetivas. [Através do processo 566-T-57, inscrição n. ${ }^{\circ} 18$ Livro Arqueológico, Etnográfico e Paisagístico, fols. 4 - em 26.VI.1958, registra o tombamento do núcleo original da Cidade pelo IPHAN. MACHADO, Lielza L. Opus. Cit. p. 79.]

Sendo deferida uma nova demarcação, de acordo com a certidão de 1786, o processo se desenrolou até o ano de $1836^{13}$. O que se verifica é que ao longo de 18 anos, o conflito pela posse da terra, ultrapassou inclusive a criação da vila de Vassouras. Em 1833, esta era uma pequena parte permutada da então Sesmaria de Vassouras e Rio Bonito. 
Mas, duas situações nos chamaram a atenção, durante a leitura deste processo: a primeira foi que, durante o segundo dia da demarcação - 15 de setembro de 1818 - consta no relatório que, ultrapassando 155 braças e um córrego de água, continuou o rumo até umas lajes de pedras com mais 26 braças e, após 25 braças, chegou-se ao rumo com a Estrada Real da Polícia que vai para a Cidade ${ }^{14}$. Nesse período, a cidade mais próxima era o Rio de Janeiro. A segunda situação nos faz concluir que já existia uma propriedade rural, com uma boa quantidade de residências, inclusive para colonos e a presença de cafezais.

\section{A Vila e Cidade de Vassouras}

Custódio Leite Ribeiro - o futuro Barão Ayuruoca -, junto com seu sobrinho Francisco José Teixeira Leite, o Coronel Ambrósio de Souza Coutinho e o Guarda-Mor João Teixeira Gomes, iniciaram em 08 de janeiro de 1828, a construção da Capela dedicada a Nossa Senhora da Conceição e em seu entorno a criação da futura Vila ${ }^{15}$. Teve também apoio da família Corrêa e Castro, através do vereador Laureanno, que atuava nesse cargo, na então Vila de Paty do Alferes. Durante uma proposta para a sua permanência ou troca de sede e com a definição de seu provável local, foi aprovada a transferência da vila para Vassouras. Com isso, Paty passou a ser Termo de Vassouras.

Apesar do nome Freguesia - hoje Paróquia -, ser de origem eclesiástica e Vila, da organização do Estado, para essa segunda ser criada havia a necessidade da existência da primeira, ou a sua criação conjunta. O que não aconteceu com a Vila de Vassouras, criada em 1833 e que teve sua Freguesia criada apenas em 1837, desmembrada, como já mencionamos, da Freguesia de Sacra Família do Tinguá ${ }^{16}$.

Visando a diminuir as dificuldades impostas pelo Caminho Novo, são criadas novas vias de comunicação entre esta região e a Corte: a Estrada do Comércio, em 1811 - que em 1815, o Capitão-Mor Custódio Ferreira Leite, juntamente com seu irmão Francisco Leite Ribeiro (arrematante da construção dessa estrada) estavam dispostos a terminar no prazo contratual; a Estrada da Polícia, criada em 1819. A Vila de Vassouras foi beneficiada com tal empreitada, visto as duas estradas cortarem o centro administrativo e por serem as principais vias do Império, na época.

Por elas passaram alguns viajantes, que deixaram suas impressões sobre a região. Entre eles destacamos: Auguste Saint-Hilaire, em 1816, que não faz nenhuma menção a povoado algum; o Reverendo Walsh, em 1829, que subiu a Estrada da Polícia em direção às Gerais e se referiu a ranchos e vendas ao longo da estrada, nos locais Graminho, Mata Cães e Bassura. Charles Ribeyrolles e Victor Frond, na segunda metade do século XIX, já encontraram uma cidade de dimensões respeitáveis, como se pode ver pela descrição do primeiro e pela vista apresentada pelo segundo. ${ }^{17}$

O Dr. Joaquim José Teixeira Leite, Presidente da Câmara Municipal de Vassouras, em seu relatório de prestação de contas, na sessão ordinária de 7 de janeiro de 1849, destacou que, mesmo em 1833, só havia, no entorno da Igreja, umas quatro ou cinco casas. ${ }^{18}$

Neste período, calculou, o dito relatório, a presença por volta de 33 mil almas (habitantes), entre livres e escravos, nas freguesias de Vassouras, Paty e Sacra Família; descreveu, ainda, cada obra realizada no período de seu mandato. Entre elas destacamos: aquisição de 
lampiões para a iluminação pública; desaterros no centro da Vila; alargamentos de pontes; plantação de árvores na praça da Matriz; construção de chafarizes, visando à melhoria no atendimento de água à população. Solicitou, ainda, aos próximos legisladores, buscarem, junto ao governo da Província do Rio de Janeiro, meios para a construção da Casa da Câmara e Cadeia.

Em seu estudo sobre a construção residencial urbana de Vassouras, Augusto da Silva Telles, reconheceu que havia uma boa harmonia entre a Irmandade de Nossa Senhora da Conceição de Vassouras e a Câmara Municipal, por terem um objetivo comum que visava ao progresso e ao perfeito desenvolvimento da Vila ${ }^{19}$.

Em nossa obra intitulada Redes de Sociabilidade em Vassouras no século XIX - O Caso Benatar $^{20}$, publicada em 2007, concluímos que a parceria citada não seria tão difícil de acontecer, pois o Procurador Geral da Irmandade e o Presidente da Câmara nesse período era a mesma pessoa, o Dr. Joaquim José Teixeira Leite. Esse, por sua vez, na posição de Procurador Geral, criou regras para agilizar a construção de imóveis, na área foreira e pertencente à Irmandade de Nossa Senhora da Conceição de Vassouras, cobrando os foros anualmente referente à posse do terreno e a benfeitorias nesse. Por uma demarcação dessas terras, tivemos a oportunidade de identificar o nome da rua, se estava do lado ocidental ou oriental da rua, o nome do foreiro, o número do lote, o tamanho da área do terreno e o valor pago pelo foro ${ }^{21}$. E, buscando facilitar o leitor, em nosso trabalho publicado e mencionado anteriormente, inserimos os nomes das ruas atualizados e também a planta dos terrenos foreiros de 1932, com a abertura de novo arruamento.

Outra situação que destacamos é a de encontrarmos sempre nas comissões de construção da Igreja, do Teatro, da Casa da Câmara e Cadeia e, também, da Casa de Caridade, um membro da família Teixeira Leite, normalmente ocupando a presidência ou a tesouraria das obras ${ }^{22}$.

Aconstrução de residências entre os anos de 1849-1860, fez crescer o comércio e incentivou o surgimento de diversas atividades e serviços na Vila. Entre eles destacamos ${ }^{23}$ : boticas, hospedarias, bilhar, padarias, oficinas diversas, canos de aluguel, açougues, olarias e advogados, médicos e cirurgiões, barbeiros, diretores de música, capitalistas, ouriveses, relojoeiros, agrimensores, mestres de obras, modistas, alfaiates, sapateiros, armadores, marceneiros, funileiros, ferreiros, ferradores, seleiros e correeiro, serralheiros, fabricantes de carroças, charuteiro, fogueteiro, sem contar as atividades rurais, propulsoras de todas as demais atividades.

Mas, foi durante a gestão do Dr. Caetano Furquim de Almeida que a Vila recebeu o calçamento das principais ruas do centro urbano e a abertura de novas ruas. Entre elas destacamos a Rua Augusta (atuais Avenidas Prefeito Henrique Borges Filho e Ministro Romeiro Neto, no Bairro do Alto do Rio Bonito). A Rua Augusta foi aberta visando ao contato com a Estrada Presidente Pedreira; as construções de pontes que cortam a área central e também a distribuição de bicas d'água, para abastecimento da população, visto ser insuficiente o chafariz D. Pedro II para atender toda a Vila. Este chafariz recebeu este nome, devido a quantia doada para sua construção ter sido feita pelo próprio Imperador em visita à Vassouras, sendo também verificado, por ele, que a água que existia na bica no final da Rua das Flores (onde atualmente é o Trevo do Imperador) era própria para o 
uso da população, tendo em vista que no chafariz do centro da praça da Concórdia (atual Praça Barão do Campo Belo) a água era de má qualidade.

E não podemos deixar de destacar que foi nesse período, para ser mais exato, em 29 de setembro de 1857, que a Vila de Vassouras foi elevada à categoria de cidade.

Com essa efervescência em serviços e atividades, a cidade tinha a necessidade de investir também na cultura, como destacamos, com a construção do teatro, na Rua das Flores - atual Visconde de Cananéa - onde hoje pode ainda ser visto o seu alicerce em pedra, assim como a sua estrutura, na litografia de Victor Frond ${ }^{24}$, feita em 1857, quando passou por Vassouras, junto com Charles Ribeyrolles. Infelizmente, essa obra não se concluiu e continuamos a ter o antigo teatro, na Travessa do Theatro, lado sul (atual Rua Rodolpho Leite Ribeiro $)^{25}$. Em 1876, Vassouras passou a ter dois teatros, estando o segundo na Rua Barão de Massambará, onde se encontram, atualmente, instalado o Centro Educacional Tia Conceição e o Colégio Peter Pan - Praça Cristóvão Corrêa e Castro.

A população da Vila e depois Cidade de Vassouras, não viveu somente de saraus e peças teatrais. Também presenciou uma insurreição de escravos em 1838, no Termo de Paty do Alferes, que deixou todos em sinal de alerta, devido ao número de escravos envolvidos e à necessidade de combatê-los, antes que chegassem ao espaço urbano. Para tanto, a Câmara, nesse período, não interrompeu suas sessões. A fim de resolver a situação o mais breve possível, a Guarda Nacional, formada por moradores locais, conseguiu capturar os envolvidos, antes mesmo da chegada do futuro Duque de Caxias, que fora enviado pelo Império para solucionar a questão.

Sendo considerado o líder da revolta, nos processos de insurreição e homicídio, o escravo Manoel Congo foi condenado à morte; as mulheres envolvidas foram inocentadas e os demais, condenados a 600 açoites.

Anos mais tarde, um novo plano envolvendo escravos de diversos lugares da província do Rio de Janeiro se organizou para uma nova insurreição, que foi coibida a tempo. Com o objetivo de se evitarem novas tentativas de insurreição escrava, uma comissão preparou um documento para orientar os fazendeiros.

Não era sem motivo a apreensão dos moradores em relação à violência que poderiam sofrer pela mão dos escravos. No período de 1850, a Vila contava com uma população de mais ou menos 10.000 habitantes, sem contar as Freguesias de Paty do Alferes e Sacra Família do Tinguá, com a proporção de 2 escravos para cada habitante livre, onde se conclui, mais ou menos, haver uma população de $70 \%$ de escravos e $30 \%$ de livres ${ }^{26}$.

Havia também muito trabalho e as famílias abastadas, lideradas pelos Teixeira Leite, fizeram de tudo para que o traçado da Estrada de Ferro Pedro II (antiga Rede Ferroviária Federal S/A - RFFSA), passasse por Vassouras. Entretanto, após estudo, chegou-se à conclusão que, passando por Barra do Piraí, o relevo favoreceria muito mais a construção da estrada. Apesar de o contrato ter sido assinado no Palacete do Barão de Vassouras, e de boa parte do capital envolvido nesta empreitada ter sido dessa família, foi a Família Faro, de Barra do Piraí, que venceu o traçado. Vale destacar que os Faro tinham laços de parentesco com o Senador Nicolau Vergueiro ${ }^{27}$.

Pôde-se contar, em 1875, com um serviço de bonde movido por tração animal, devido à 
carência nos serviços de transporte, visto só existirem as carruagens e diligências, com um custo alto para aqueles que necessitavam desse serviço. O percurso do serviço de bonde era: Rua Bonita (atual Caetano Furquim), Largo do Cemitério da Conceição (atual Praça Cristóvão Corrêa e Castro), Rua Direita (atual Barão de Massambará), Beco do Tenente Souza (hoje Ana Jesuína), Rua das Flores (hoje Visconde de Cananéa) e Rua do Comércio (atual Barão de Vassouras), de onde partia para a Estrada do Rio das Mortes (hoje distrito de Barão de Vassouras), onde iria encontrar o trem da Estrada de Ferro D. Pedro II. A viagem de bonde levava quarenta e cinco minutos ${ }^{28}$.

Somente em 1883, Vassouras contaria com um ramal da ferrovia passando por dentro da Vila, sendo que o trilho desse trem era de meia bitola, da estação de Vassouras até o distrito de Barão de Vassouras. A cidade foi perdendo muito do seu movimento, devido ao traçado da ferrovia. Por sua vez, os locais onde eram instaladas as estações, começaram a se desenvolver; o comércio de Vassouras perdeu sua freguesia, pois a atividade de tropeiros deixou de ser necessária, já que havia o trem para o transporte do café. Logo as estradas do Comércio e da Polícia, perderam o movimento de tropas e caixeiros. Sobre esta estagnação, nos fala o jornalista Francelino Marques, que declara numa coluna do Jornal Vassourense, em sua primeira edição em 1882, um pouco sobre o cotidiano do início dos anos sessenta do século XIX,

\footnotetext{
Já não se encontra nela a vida, a animação, o movimento(...). Naquela época o ruído dos carros, o tropel dos animais, o grito das crianças, o pregão dos vendedores de toda a casta de frutas e de doces, o cruzar dos cavaleiros no caminho, o ladrar dos cães vadios nas estradas que conduzem a este outrora, rico empório de mercadorias, das brigas dos moleques de rua, e, nas casas de negócios, as conversas calorosas que, as mais das vezes, se tornavam em vivas e impertinentes disputas, quando não em cenas de pugilato; as lutas ardentes dos partidos que então se degladiavam com mais furor que atualmente. (...) (MONTEIRO, Angelo F., 2007, Nota de rodapé 68. p. 54)
}

Outra situação difícil, enfrentada pelos moradores, foi a epidemia de febre amarela, que assolou o município em dois momentos, nos anos de 1880 e $1881^{29}$.

A Câmara Municipal tratou logo de tomar algumas providências, entre elas o fechamento do Cemitério da Conceição e a criação de um novo cemitério, muito criticada esta atitude, tendo em vista que o cemitério se encontrava muito próximo da cidade (Avenida Octávio Gomes, onde se encontra hoje o Supermercado Bramil) e em menos de dois anos já se encontrava cheio. A solução encontrada foi retirar os restos mortais e enviar para um ossário especialmente construído no Cemitério Municipal, retirado, de uma vez por todas, do centro da cidade ${ }^{30}$.

Na primeira edição do seu Jornal, intitulado "O Vassourense" de 1882, o médico Lucindo Filho, destacou em seu editorial como se encontrava a cidade de Vassouras,

... dentro dos muros da cidade, a população não atinge, com certeza, ao número de duas mil almas e em sua estrutura: 18 casas de negócios, 3 padarias, 2 hotéis, 4 botequins, 5 alfaiates, 6 modistas, 4 sapateiros, 4 funileiros-caldeireiros, 4 estabelecimentos de carros e 1 dito na Santa Casa de Misericórdia, 2 farmácias, 6 médicos, 13 advogados, 5 
solicitadores, 2 colégios de meninas, 1 dito de instrução primária (aula pública) e 1 dito de instrução secundária) (MONTEIRO, Angelo F. , 2007, Nota de rodapé 68. p. 55.)

Nota-se, a partir destes dados, o caos que a cidade se transformou após a epidemia de febre amarela e, também, pela estrada de ferro, com o êxodo urbano e a diminuição de serviços e atividades comerciais.

\section{Vassouras na República}

Devido à insatisfação dos grandes agricultores com o regime monárquico do Brasil, por ter deixado de lado aqueles que o mantinham, levando, inclusive, entre seus nobres, que viviam na cidade de Vassouras, a receber em 1889, com muita festa a introdução do sistema republicano. Vários fatores foram relevantes para tal atitude, ao longo do segundo reinado: as políticas de emancipação do trabalho escravo de forma gradativa, a proposta de uma possível reforma agrária e a possibilidade de um terceiro reinado, tendo a frente a Princesa Isabel. Tais fatores levaram a imprensa, inclusive a local, que era formada por intelectuais e era defensora dos ideais republicanos, a atacar a monarquia no Brasil, classificando-a como "elefante branco" e "planta exótica da América"31.

O principal propagador das ideias do Partido Republicano em Vassouras, foi o Dr. Sebastião Eurico Gonçalves de Lacerda, primeiro vereador republicano eleito no município, essencialmente monarquista ${ }^{32}$. Várias personalidades, inclusive da nobreza, assinaram o manifesto do Clube Republicano de Vassouras, contra o atual sistema monarquista ${ }^{33}$.

No dia seguinte à proclamação da república, o município foi informado do novo regime implantado. E no dia 19 de novembro, a Câmara se reuniu em sessão solene, para festejar, sessão essa, iniciada pelo hino francês "A Marselhesa" 34 .

Falar de política e não citar a família Lacerda, é quase impossível, visto o Dr. Sebastião ter ocupado também os cargos de Ministro de Estado e de Ministro do Supremo Tribunal Federal. Com toda essa atividade pública foi homenageado em Vassouras, com a praça atrás da Igreja Matriz de Nossa Senhora da Conceição de Vassouras, que leva o seu nome e onde foi colocado seu busto de bronze, considerado o primeiro monumento da cidade de Vassouras.

Mas foi seu filho, Maurício Paiva de Lacerda, que, seguindo os passos paternos, enveredouse pelos caminhos da política, sendo vereador, prefeito e deputado. Na sua atuação como prefeito de Vassouras, a cidade sofreu várias mudanças na área urbana. Tais mudanças ocasionaram o surgimento de insatisfação por parte dos moradores, que achavam as suas ideias arbitrárias ${ }^{35}$. Defendia que eram necessárias algumas obras de adequação, no centro da cidade de Vassouras, principalmente para as festividades do centenário de criação de Vassouras.

Um dos insatisfeitos com esta situação foi o proprietário de um imóvel situado na Travessa 3 de Outubro (atual Praça Athayde Parreiras), com esquina para a Rua Dr. Joaquim Teixeira Leite ${ }^{36}$.

Aconteceu que, exatamente às 7h30min da manhã do dia 13 de março de 1934, funcionários 
da Prefeitura chegaram à frente do imóvel para executar uma ordem do prefeito: a destruição do passeio público em frente dita propriedade, que apresentava um armazém de secos e molhados, armarinho, bazar e ferragens. Contrário à execução, o proprietário ouviu do próprio Diretor de Higiene da Prefeitura, que, seguindo as ordens do prefeito, "usaria a força armada se necessário fosse para a conclusão dos trabalhos"37.

Preocupados com a segurança de seu patrimônio, devido à ameaça de nova investida por parte dos funcionários da Prefeitura, foi obrigado a solicitar um mandado proibitório e a intimação de testemunhas para comprovar a sua defesa. Todos as três testemunhas ${ }^{38}$, afirmaram que, apesar da divergência, o proprietário e sua família, sempre se mantiveram de forma delicada, mas enérgica, não consentindo na consumação dos trabalhos.

Um indivíduo, apesar de não ser morador de Vassouras, afirmou que desde o dia anterior estava ciente do ato que a prefeitura desejava executar, pois muitas pessoas declararam este fato (...) sendo presenciada a tentativa por diversos curiosos, que ali estavam, para assistir à destruição do passeio e à demolição de parte do prédio. Verificou-se, na ocasião, que o novo alinhamento cortava parte da frente do prédio. E, na segunda tentativa, os funcionários estavam acompanhados do delegado (...), que trazia um documento que requisitava a força policial. Ao saberem do que se tratava, os proprietários disseram que só aceitariam se fosse um Mandado Judicial.

Discordando dos autores da ação, a prefeitura, se justifica dizendo que, as obras de nivelamento da travessa, vêm levantando os lajedos que constituem os passeios laterais e que, "jamais pretende cometer a absurda e descabida violência de demolir o prédio de propriedade dos autores".

E ainda inconformada por que seu intento não haver sido alcançado, a Prefeitura solicitou, ao Juiz, um perito para vistoriar o prédio e o passeio fronteiro, havendo a necessidade, também, da citação de moradores da cidade, juntamente com o guarda de armazém na Estação de Vassouras, da Estrada de Ferro Central do Brasil, como testemunhas, a notificação do perito e a inclusão da planta referente ao local da ação judicial ${ }^{39}$.

As testemunhas solicitadas pela prefeitura, apesar de não estarem presentes no primeiro momento ou mesmo não se lembrarem do dia que aconteceu a divergência, disseram, primeiramente, ${ }^{40}$, não ter escutado de nenhum funcionário da prefeitura a intenção de demolir o prédio. Um outro ${ }^{41}$ relata que fora informado pelos próprios funcionários municipais, entre eles o fiscal, da pretensão de retirar o passeio em frente ao prédio, aproveitando os lajedos na feitura dos meios-fios, para serem colocados no mesmo local, como se tem feito, em outras ruas da cidade. O terceiro a depor ${ }^{42}$ recorda-se apenas de ser chamado para testemunhar o fato de a prefeitura retirar os lajedos. Esse último, sendo inquirido pelos advogados dos autores, confirmou que tinha de fato um filho, empregado da Prefeitura, onde exerce o cargo de servente e que seus vencimentos estavam sendo pagos em dia.

Se não havia a intenção da Prefeitura de demolir o prédio, qual era o motivo para solicitar a presença de testemunhas e a realização de uma vistoria não só no passeio público como também no prédio?

Pela conclusão de uma das testemunhas dos autores, a retirada do lajedo, não efetivava 
a intenção da prefeitura, mas com o novo desenho, o prédio passaria a atrapalhar a via pública. E, no relatório de conclusão, provou-se que havia sim, a necessidade de demolição da construção dos autores, apesar de a prefeitura negar sua intenção.

Inclusive, como pode se perceber pelas declarações do advogado dos autores

... Estes comezinhos princípios de direito civil sobre os direitos reais é que deviam existir na cabeça descabelada do bacharel político que serve como Prefeito Municipal, para que não julgue que tem direito absoluto sobre tudo e sobre todos, como a sua mania de mandonismo o persuade, infelizmente para os seus munícipes. (...) a Ré tem o desplante de confessar que pretende destruílo para colocar o meio fio, como se uma servidão de trânsito quase secular, existente desde a construção do prédio, talvez há mais de 80 anos, pudesse ser destituída por um simples capricho de um regulete de aldeia. (Interdito Proibitório - 1934. p. 67).

E, alfineta o advogado do prefeito, dizendo que este deveria ler

.... um pouco das doutrinas sobre servidões, (...) para não continuar com a mesma extravagante ideia e assim, não ficar um dia impossibilitado de entrar em casa, quando um prefeito semelhante ao de Vassouras, mandar arrancar o passeio da casa que habitar e deixar em seu lugar um buraco de alguns metros de profundidade. (Interdito Proibitório - 1934. p. 68)

E conclui que o prefeito,

... Impossibilitado pela resistência dos autores que estavam dispostos a todas reações para se garantir na posse de seus direitos sagrados sobre a sua propriedade, vem ele agora dizer que nada pretendia fazer, não assumindo a responsabilidade de seus atos, com é seu hábito fazer em toda a sua vida, e como já fez em 1925, na prisão da Ilha de Bom Jesus, fugindo a confirmação do que ouvira do Tenente Alvarez na presença do Capm. Goytacazes. (Interdito Proibitório - 1934. p. 69 v.)

E se insere nos autos do processo, uma carta de dezembro de 1932, do prefeito Maurício de Lacerda para o proprietário do imóvel, que abaixo descrevemos

Vassouras, 14 de dezembro de 1932.

Prezado amigo e conterrâneo (...).

Saúde a V. Venho, conforme conversações anteriores, dizer-lhe que já fiz traçar o alinhamento da Rua Barão de Vassouras até a esquina da Rua 3 de Outubro. Por esse alinhamento o seu prédio fica no meio da rua. Assim terei de fazer que recue. Estando próximo o Centenário desejaria poder corrigir a entrada da cidade que é, por assim dizer, esgoto de água pluvial, e, ao mesmo tempo que modernizar a rua, calça-la a paralelepípedos.

Conto com a sua boa vontade e cooperação para essa grande medida, desde que o terreno que lhe sobejará, e prédio, serão além de tudo valorizados por essa obra, circunstância que deverá regular as bases do nosso acordo. Certo de que, no mais breve prazo terei a sua boa resposta, sou seu amigo. Obrigado Atenciosamente, 


\author{
Mauricio Paiva de Lacerda \\ Prefeito (Interdito Proibitório - 1934. p. 76.)
}

Pode-se notar pela carta, do prefeito Maurício de Lacerda, que o prédio em questão, com o novo traçado, iria ficar no meio da rua. Afirmava ainda, que o proprietário deveria recuar a área avançada, visando a regular a entrada da cidade para as festividades do centenário de elevação à cidade, em 15 de janeiro de 1933. É evidente que as tentativas do poder municipal em padronizar a urbanização da cidade ultrapassaram as festas do Centenário, visto que a ação judicial fora aberta em 13 de março de 1934.

E, se era intenção do prefeito preparar a cidade e principalmente o seu centro urbano para as festividades do centenário, por que motivos a correspondência fora expedida em pouco mais de um mês de antecedência do dia do centenário? Estaria o Poder público com a certeza de poder contar com o apoio da população e de alguns moradores, como nesse caso específico, inclusive com a perda de uma propriedade particular, sem as devidas providências legais de desapropriação?

Constava ainda, inclusa na ação judicial, uma escritura de doação de terras feitas pelo proprietário do imóvel à prefeitura ${ }^{43}$. Aos ataques pessoais não se perdeu tempo em respondê-los. Para encerrar o caso, o prédio foi vendido em 27 de novembro de $1934^{44}$.

Alguns meses depois, a prefeitura sofreu mais uma ação judicial, por um morador indignado com as obras em frente do seu imóvel, situado à Rua Visconde de Araxá e, buscando defender seus interesses, questionou a retirada das lajes do passeio e a sua transformação em meios-fios, não entendendo o motivo da substituição, pois as lajes se encontravam em perfeito estado de conservação, por serem de granito, em forma quadrangular e de superfície lisa, com nivelamento dado pela Câmara Municipal, há mais de 60 anos, quando os primeiros proprietários pagaram através de quotas o calçamento de toda cidade ${ }^{45}$.

Acusava o Poder Público de se utilizar da sua posição para publicar decretos/deliberações e obrigar os moradores na construção de um novo passeio público e o pagamento de parte do calçamento que estava sendo feito, embora, segundo o morador, a dita rua em que residia estava calçada regularmente e era considerada a melhor da cidade ${ }^{46}$.

Sentindo-se, o morador, coagido pelos atos emanados da municipalidade, solicitou a intimação do prefeito Dr. Maurício de Lacerda e informou que, se este não fosse encontrado nessa cidade que poderia sê-lo em sua residência à Rua Buarque de Macedo, n. ${ }^{\circ}$ 18, no Distrito Federal (atual cidade do Rio de Janeiro). O prefeito ficou ciente da intimação em Vassouras em 30 de junho de $1934^{47}$.

\title{
Considerações Finais
}

Durante a construção deste trabalho, tivemos a oportunidade de verificar que a escolha do local para a construção da Vila e posterior Cidade de Vassouras, não foi algo impensado, todo o processo foi cheio de intencionalidades. A primeira visão que defendemos é o projeto de $\operatorname{cidade}^{48}$, que nasceu pela rede clientelista formada pelos laços de parentesco, 
das famílias Teixeira Leite, Almeida e os Corrêa e Castro, implantado, ainda no século XIX, por essas uniões. As duas primeiras, ainda em Minas Gerais e a terceira, proprietária de terras no centro de Vassouras, puderam erguer a Vila, transferindo-a de Paty do Alferes, onde Laureano Corrêa e Castro (Barão do Campo Bello) era vereador e proprietário das terras, onde se encontra a praça que recebeu seu nome. ${ }^{49}$ Esse terreno foi doado pela sua família na década de $1870^{50}$. A segunda, pela permuta de terras realizada por Francisco José Teixeira Leite (Barão de Vassouras) com os descendentes de Francisco Rodrigues Alves e Luiz Homem de Azevedo. A terceira, por ser o local escolhido cortado pelas duas principais estradas da época, a da Polícia e a do Comércio, sendo esta última aberta por Custódio Leite Ribeiro (Barão Ayuruoca), ligado por laços de parentesco com os Teixeira Leite.

Mas, foi na administração de Caetano Furquim de Almeida, como Presidente da Câmara, da época, que a Vila recebeu os primeiros arruamentos e seu calçamento, com o apoio da Irmandade, proprietária das terras e, para ser mais específico, do procurador da Irmandade e seu antecessor na Câmara, o Dr. Joaquim José Teixeira Leite. Vale lembrar que Caetano Furquim casou-se com a filha de Francisco José Teixeira Leite. Com o falecimento de sua esposa, Caetano Furquim casou-se, em segundas núpcias, com a sua cunhada, visando à manutenção dos laços de parentesco ${ }^{51}$.

O que se deixa transparecer é que toda a cidade foi criada num negócio de família, de interesses, não apenas particulares, mas cheios de realizações - como a implantação da principal ferrovia da Província (atual Estado) do Rio de Janeiro, infelizmente não passando por Vassouras, como era intenção da família Teixeira Leite. Outras realizações conseguiram chegar até os nossos dias, inclusive no Centro Histórico, como a permanência do calçamento feito na época, a Igreja Matriz e a Câmara Municipal, entre outras.

O plano urbano sofreria alterações com a ideia de modernização proposta por Maurício de Lacerda, na década de 30, do século XX, com o intuito de transformar Vassouras em cidade turística, normatizando o espaço urbano, no que diz respeito aos arruamentos, em alguns pontos que se tornaram problemáticos no período das chuvas, com a iluminação das praças, a arborização da cidade e a permanência de alguns prédios do período áureo da cidade com substituição daqueles que estavam desmoronando.

Através do seu plano de ação, Maurício de Lacerda, levou a população a refletir, sobre a cidade ideal em que gostariam de morar.

Percebemos que, em um dos processos, através da correspondência enviada pelo prefeito ao morador, o primeiro solicitava que havia a necessidade do recuo da sua construção, para que o imóvel não ficasse no meio da rua. Ficou declarado aqui, que havia a necessidade da demolição do prédio em questão.

Pelos estudos que estão sendo realizados, poderá a cidade de Vassouras, receber mais esta contribuição, por ser o período republicano tão pouco estudado. E as gerações futuras terão o direito de conhecer a atuação do prefeito Maurício Paiva de Lacerda, que não deixou passar em branco o seu nome. Em seu momento histórico, foi incompreendido em seus atos, mas ainda hoje podemos presenciar o legado por ele deixado à cidade. 


\section{Notas}

1 TAMBASCO, José Carlos V. A Vila de Vassouras e as Freguesias do Tinguá - Um Abordagem social e econômica dos tempos da colonização. Vassouras, Editor Autor, 2004. e NOVAES, Adriano. Os Caminhos Antigos no Território Fluminense. Endereço: $<$ http://www.institutocidadeviva.org.br/inventarios/sistema/wp-content/uploads/2008/06/ oscaminhosantigos.pdf $>$ acesso 22 jan 2009. Este último autor utilizou também como fonte os trabalhos de José C. V. Tambasco, configurando em seu texto um mapa com todas as variantes do Caminho Novo.

2 TAMBASCO, José Carlos V. Opus Cit. p. 19. As Jornadas são destacadas a cada percurso alcançado e também o uso de variantes do caminho, que poderiam contribuir na diminuição do trajeto.

3 SOUZA, Alan de C. Querelas Políticas: Outra História no Caso Manoel Congo. Monografia de Conclusão do Curso de Licenciatura Plena em História da Universidade Severino Sombra. Vassouras/RJ., defendida em 2008.

4 BITTENCOURT, Fernando M. Vassouras, um pouco de sua história. Vassouras, Gráfica Palmeiras, 2001. p. 22.

5 TELlES, Augusto Carlos da S. Vassouras, Estudo da Construção Residencial Urbana. Separata da Revista do Patrimônio Histórico e Artístico Nacional. Vol. 16. Rio de Janeiro, 1968. p. 22.

6 Medição e Demarcação - 1818. Partes: José Teixeira Gomes e Antonio Alves de Lacerda (autores); Luiz Homem de Azevedo e Fellis Rodrigues Alves (falecidos). Sesmaria de Bassouras e Rio Bonito - Vassouras. Documento Incompleto. (Código 101663451016) Centro de Documentação Histórica da Universidade Severino Sombra. Convênio Tribunal de Justiça do Estado do Rio de Janeiro e Fundação Educacional Severino Sombra (doravante TRERJ - CDH da FUSVE/USS).

7 MACHADO, Lielza L. Vassouras - Recanto Histórico do Brasil. $3^{\mathrm{a}}$ ed. Vassouras, Gráfica Palmeiras, 2006. p. 21.

8 BRAGA, Greenhalgh H. F. Vassouras de ontem. Rio de Janeiro, Cia. Brasileira de Artes Gráficas, 1975.p.79

9 Através do processo 566-T-57, inscrição n. ${ }^{\circ} 18$ Livro Arqueológico, Etnográfico e Paisagístico, fols. 4 - em 26.VI.1958, registra o tombamento do núcleo original da Cidade pelo IPHAN. MACHADO, Lielza L. Opus. Cit. p. 37.

10 Idem. p. 35 a 38.

11 Idem. p. 68 a 74.

12 Idem. p. 75.

13 Idem. O processo em si, encontra-se muito danificado e incompleto, algumas de suas páginas estão corroídas dificultando a leitura de algumas partes.

14 Idem. p. 42 v.

15 BITTENCOURT, Fernando M. Opus Cit. p. 22 e 23

16 TAMBASCO, José Carlos V. Opus Cit. p. 21 e 31.

17 TELLES, Augusto Carlos da S. Vassouras, Estudo da Construção Residencial Urbana. Separata da Revista do Patrimônio Histórico e Artístico Nacional. Vol. 16. Rio de Janeiro, 1968. p. 22. 
18 TELLES, Augusto Carlos da S. Opus Cit. p. 22 e 23. e BRAGA, Greenhalgh H. F. Opus cit. p. 119 a 124.

19 TELlES, Augusto Carlos da S. Opus Cit.p. 1.

20 MONTEIRO, Angelo F. Redes de Sociabilidade em Vassouras no século XIX - O Caso Benatar. Vassouras, Editor Autor, 2007.

21 Idem. p. 28 a 37.

22 MONTEIRO, Angelo F. Opus Cit. p. 51.

23 Idem.p. 49 e 50.

24 RAPOSO, Ignácio. História de Vassouras. $2^{\mathrm{a}}$ ed. Niterói, SEEC-RJ, 1978. p. 118.

25 MONTEIRO, Angelo F. Opus Cit. p. 22.

26 MONTEIRO, Angelo F. Opus Cit. p. 46.

27 IÓRIO, Leoni e IÓRIO, Jorge Luiz D.. Terceiro Barão do Rio Bonito - Subsídios para a História de Barra do Piraí. $1^{a}$ Ed.. Ampliação e edição de Jorge L. Dutra Iório. Juiz de Fora, Di Gráfica e Editora Ltda., 2007. p. 51.

28 RAPOSO, Ignácio. Opus Cit. p. 164.

29 RAPOSO, Ignácio. Opus Cit. p. 171.

30 Idem. p. 174.

31 MONTEIRO, Angelo F. e LIMA, Ailton B. A Política no Brasil do Século XIX: O Olhar do Jornal "Vassourense - 1882 a 1887". In: CD-ROM do IV Encontro de Iniciação Científica da Universidade Severino Sombra, Vassouras, 2005.

32 RAPOSO, Ignácio. Opus Cit. p. 196.

33 PINTO, Jorge. Fastos Vassourenses. Vassouras, Editora Fundação $1^{\circ}$ de Maio, 1935. p. 298304.

34 RAPOSO, Ignácio. Idem.

35 Citamos duas pesquisas que foram desenvolvidas sobre este tema: O Visionário Maurício de Lacerda e a tentativa de modernização urbana, das autoras Cinthia Rocha e Renata Vereza, que usaram como fontes o "Jornal de Vassouras" e o Diário Oficial 1932 a 1935 onde encontraram os decretos legais que originaram na imprensa a publicação de protestos e de contestação sobre tais obras. Perceberam também que a tentativa de Maurício de Lacerda de conservar os grandes monumentos da cidade, que guardavam a memória dos tempos áureos, embora estes se encontrassem bastantes deteriorados e nas palavras do prefeito "a cidade já havia perdido o viço". E também o caráter de modernização de seu "plano de urbanização", corroborado pelas festividades do centenário e a ambição para transformar Vassouras em uma cidade turística. E concluíram que as alterações sofridas pela cidade, são frutos das ideias de Maurício de Lacerda e lamentam que a memória coletiva tenha "se esquecido" dessa figura ímpar e os poucos que se recordam o descrevem como "um excêntrico que abria ruas durante a madrugada e surpreendia os moradores na manhã seguinte". A outra pesquisa desenvolvida por Lucia Silva, com o apoio dos alunos do Projeto Jovens Talentos para a Ciência da FAPERJ/ CECIERJ, Nelson Henrique Ribeiro Júnior e Richard Lopes Rodrigues, intitula-se $O$ Jornal O Município e discussões urbanas na cidade de Vassouras 1920/45. Lúcia Silva, percebeu que o prefeito Maurício de Lacerda foi um importante personagem na discussão do Conselho Municipal do Distrito Federal, para a contratação de um urbanista estrangeiro em 1927 e o responsável pelo confecção do primeiro plano diretor para a cidade do Rio de Janeiro, o Plano Agache em 1930. O principal objetivo deste projeto foi conhecer como se estruturou a 
corrente em que Maurício de Lacerda era representante, denominada na historiografia como antiurbana.

36 Interdito Proibitório - 1934. Prefeitura Municipal de Vassouras (suplicada). (Código 103666132021) - Convênio: TRERJ - CDH da FUSVE/USS. p. 02.

37 Idem. p. 02 e verso.

38 Idem. p. 11 verso a 12 verso.

39 Idem. p. 33 a 40.

40 Interdito Proibitório - 1934. p. 48 e verso.

41 Idem. p. 49 e verso.

42 Idem. p. 50 e verso.

43 Idem. p. 70.

44 Interdito Proibitório - 1934. p. 76.

45 Protesto Judicial - 1934. Prefeitura Municipal de Vassouras (suplicada). (Código 103666126021) - Convênio: TRERJ - CDH da FUSVE/USS. p. 02. O processo apesar de completo, não nos traz nenhuma informação sobre o que aconteceu posteriormente, se as obras foram interrompidas ou se o prefeito conseguiu levar a frente seu projeto.

46 Idem.

47 Idem. p. 02 verso a 06.

48 MONTEIRO, Angelo F. Opus Cit. p. 85.

49 MACHADO, Lielza L. Opus Cit. p. 51. Segundo esta autora a praça criada em 1835, recebeu várias denominações: Jardim Público, Praça da Concórdia, Largo da Matriz, Largo do Chafariz, Praça do Comércio, Praça Aquidaban e por último Barão de Campo Belo (Laureano Corrêa e Castro) que a criou.

50 MONTEIRO, Angelo F. Igreja Matriz de Nossa Senhora da Conceição de Vassouras - 180 Anos de História. In: O Semeador em Revista. Paróquia de Nossa Senhora da Conceição de Vassouras. Vassouras, Gráfica Palmeiras, 2008.

51 MONTEIRO, Angelo F. Política e Cultura no Rio de Janeiro: a sociabilidade em Vassouras no século XIX. In: FERNANDES, Neusa e COELHO, Olinio G. P. (org.). Opus Cit. 2008, p. 385 a 400.

\section{Fontes Primárias}

Centro de Documentação Histórica da Universidade Severino Sombra. Convênio Tribunal de Justiça do Estado do Rio de Janeiro e Fundação Educacional Severino Sombra:

. Medição e Demarcação - 1818. Partes: José Teixeira Gomes e Antonio Alves de Lacerda (autores); Luiz Homem de Azevedo e Fellis Rodrigues Alves (falecidos). Sesmaria de Bassouras e Rio Bonito - Vassouras. Documento Incompleto. (Código 101663451016).

. Interdito Proibitório - 1934. Prefeitura Municipal de Vassouras (suplicada). (Código 103666132021).

- Protesto Judicial - 1934. Prefeitura Municipal de Vassouras (suplicada). (Código 103666126021). 


\section{Referências}

NOVAES Adriano. Os Caminhos Antigos no Território Fluminense. Endereço: $<$ http:// www.institutocidadeviva.org.br/inventarios/sistema/wp-content/uploads/2008/06/ oscaminhosantigos.pdf $>$ acesso em 22 janeiro 2009.

BRAGA, Greenhalgh. H. F. Vassouras de ontem. Rio de Janeiro, Cia. Brasileira de Artes Gráficas, 1975.

BITTENCOURT, F. M. Vassouras, um pouco de sua história. Vassouras, Gráfica Palmeiras, 2001.

FERNANDES, Neusa. Os Caminhos do Ouro. In: Revista do Instituto Histórico e Geográfico de Vassouras. Vassouras, IHGV, 2004.

FERNANDES, Neusa e COELHO, Olinio G. P. (org.). História e Geografia Fluminense. Rio de Janeiro, Instituto Histórico e Geográfico do Rio de Janeiro e Conselho Regional de Engenharia e Arquitetura e Agronomia do Estado do Rio de Janeiro, 2008.

IÓRIO, Leoni e IÓRIO, Jorge Luiz D. Terceiro Barão do Rio Bonito - Subsídios para a História de Barra do Piraí. 1 ${ }^{a}$ Ed.. Ampliação e edição de Jorge L. Dutra Iório. Juiz de Fora, Di Gráfica e Editora Ltda, 2007.

MACHADO, Lielza L. Vassouras - Recanto Histórico do Brasil. $3^{\mathrm{a}}$ ed. Vassouras, Gráfica Palmeiras, 2006.

MONTEIRO, Angelo F. e LIMA, Ailton B. A Política no Brasil do Século XIX: O Olhar do Jornal "Vassourense - 1882 a 1887". In: CD-ROM do IV Encontro de Iniciação Científica da Universidade Severino Sombra, Vassouras, 2005.

MONTEIRO, Angelo F. Redes de Sociabilidade em Vassouras no século XIX - O Caso Benatar. Vassouras, Editor Autor, 2007.

Igreja Matriz de Nossa Senhora da Conceição de Vassouras - 180 Anos de História. In: O Semeador em Revista. Paróquia de Nossa Senhora da Conceição de Vassouras. Vassouras, Gráfica Palmeiras, 2008.

PINTO, Jorge. Fastos Vassourenses. Vassouras, Editora Fundação $1^{\circ}$ de Maio, 1935.

RAPOSO, Ignácio. História de Vassouras. 2a ed. Niterói, SEEC-RJ, 1978.

ROCHA, Cinthia M. M. e VEREZA, Renata. O Visionário Maurício de Lacerda e a tentativa de Modernização Urbana. In: CD-ROM do IV Encontro de Iniciação Científica da Universidade Severino Sombra (ENIC-USS), realizado em maio de 2005.

SILVA, Lucia e RIBEIRO JÚNIOR, Nelson H. e RODRIGUES, Richard L. O Jornal O Município e discussões urbanas na cidade de Vassouras 1920/45. In: CD-ROM do VI Encontro de Iniciação Científica da Universidade Severino Sombra (ENIC-USS), realizado em 2007.

SOUZA, Alan de C. Querelas Políticas: Outra História no Caso Manoel Congo. Monografia de Conclusão do Curso de Licenciatura Plena em História da Universidade Severino Sombra. Vassouras/RJ., defendida em 2008.

TAMBASCO, José Carlos V. A Vila de Vassouras e as Freguesias do Tinguá - Um Abordagem social e econômica dos tempos da colonização. Vassouras, Editor Autor, 2004. 
. A Vila de Vassouras e o vale médio do Paraíba - A conquista da terra e a formação das bases agrícolas (1780-1833). Vassouras, Editor Autor, 2007.

TELLES, Augusto Carlos da S. Vassouras, Estudo da Construção Residencial Urbana. Separata da Revista do Patrimônio Histórico e Artístico Nacional. Vol. 16. Rio de Janeiro, 1968.

STEIN, Stanley J. Vassouras, um município brasileiro do café (1859-1900). Rio de Janeiro, Nova Fronteira, 1990. 